NBER WORKING PAPER SERIES

COORDINATION VS. DIFFERENTIATION IN A STANDARDS WAR:

56K MODEMS

Angelique Augereau

Shane Greenstein

Marc Rysman

Working Paper 10334

http://www.nber.org/papers/w10334

NATIONAL BUREAU OF ECONOMIC RESEARCH

1050 Massachusetts Avenue

Cambridge, MA 02138

March 2004

The views expressed herein are those of the authors and not necessarily those of the National Bureau of Economic Research.

(C2004 by Angelique Augereau, Shane Greenstein, and Marc Rysman. All rights reserved. Short sections of text, not to exceed two paragraphs, may be quoted without explicit permission provided that full credit, including (C) notice, is given to the source. 
Coordination vs. Differentiation in a Standards War: 56K Modems

Angelique Augereau, Shane Greenstein, and Marc Rysman

NBER Working Paper No. 10334

March 2004

JEL No. L15, L63, L86

\section{ABSTRACT}

56K modems were introduced under two competing incompatible standards. We show the importance of competition between Internet Service Providers in the adoption process. We show that ISPs were less likely to adopt the technology that more competitors adopted. This result is particularly striking given that industry participants expected coordination on one standard or the other. We speculate about the role of ISP differentiation in preventing the market form achieving standardization until a government organization intervened.

Angelique Augereau

McKinsey and Co.

Shane Greenstein

J.L. Kellogg School of Management

Leverone Hall

2001 Sheridan Road

Evanston, IL 60208-2013

and NBER

greenstein@kellogg.northwestern.edu

Marc Rysman

Department of Economics

Boston University

270 Bay State Rd.

Boston, MA 02215

mrysman@bu.edu 


\title{
Coordination vs. Differentiation in a Standards War: 56K Modems*
}

\author{
Angelique Augereau \\ Shane Greenstein \\ McKinsey and Co. \\ Kellogg School of Management \\ Marc Rysman \\ Boston University
}

February 13, 2004

\begin{abstract}
56K modems were introduced under two competing incompatible standards. We show the importance of competition between Internet Service Providers in the adoption process. We show that ISP's were less likely to adopt the technology that more competitors adopted. This result is particularly striking given that industry participants expected coordination on one standard or the other. We speculate about the role of ISP differentiation in preventing the market from achieving standardization until a government organization intervened. JEL: L15, L63, L86
\end{abstract}

\section{Introduction}

This paper studies the role of Internet Service Providers in the 56K standards war. Introduced in 1997, 56K modems allowed for data transfer at up to twice the speed of the previous technology at a time when the demand for large files (such as graphics) over the Internet became increasingly important. Originally, there were two competing standards. The standards were functionally identical in the sense that they had the same performance characteristics. However,

\footnotetext{
${ }^{*}$ We thank seminar audiences at the SED 2002 meetings, Brown University, the Department of Justice, the University of Illinois and Pennsylvania State University, the AEA 2003 meetings, the Federal Reserve Bank of Chicago, Northwestern University, Syracuse University and the Graduate School of Business at Stanford University. We also thank Tim Bresnahan, David Dranove, Mike Mazzeo, Ariel Pakes, Greg Rosston and Katja Seim for helpful comments. Martino De Stefano provided excellent research assistance. This research was supported by NSF Grant SES-0112527 and a grant from NET Institute.
} 
these standards were incompatible. If a consumer used one standard and the consumer's Internet Service Provider (ISP) used the other standard, then data transfer speed diminished to that of the previous technology, only $33 \mathrm{~K}$ or $28 \mathrm{~K}$.

In this setting we study the role of competition in technology adoption by ISPs. Despite much theoretical interest in adoption of new technologies and the competition between alternatives standards, very little empirical research examines demand for technology and how demand shapes competitive behavior. Data needs are the primary impediment. We rarely observe competition between two comparable technologies played out in more than one market. Even when that occurs, it is often difficult to disentangle the effects of competition from other important effects.

This study's setting is uniquely well suited to meet these requirements. An important feature of the ISP market is that consumers almost always connect to ISPs within their local telephone calling plan. This creates numerous geographically distinct or partially overlapping markets, which leads to geographically dispersed decision making and a variety of competitive interactions. We will study over 2200 ISPs in 2300 calling areas. Thus, we are able to compare decisions across markets, where a variety of factors shape decision making, such as the competitive and demographic environment and ISP size and previous technology.

We focus on understanding the role of competition in adoption by an ISP. We highlight findings about our central hypothesis, that competition between ISPs shaped decision making over modem choice. We show that competition consistently pushed behavior in a specific direction. ISP's were less likely to adopt a standard as more of their competitors adopted that standard. We also show that the magnitude of change could be the most important to outcomes, though we caution that this latter finding does not hold for every model.

We employ three modeling approaches: simple statistics about agglomeration, a bivariate probit model of technology adoption, and a bivariate probit 
model with controls for endogeneity. Specifically, simple statistics illustrate a prevalence towards "even splits" in local markets. That is, adopting ISP's were more likely to be evenly split between the two standards than would be predicted by independent random choice. Estimates from bivariate probit models show the same prevalence. We estimate each ISP's choice over adoption of the two technologies as a function of the competitive environment, local demographics, ISP characteristics and ISP decision-making across multiple markets. The same prevalence also arises, though more weakly, when the model accounts for possible endogeneity between the choices of competing ISP's. The estimates that control for endogeneity push our data as far as they will go. It contains novel features which we describe in detail in the text.

Theories about standardization discuss the role of competitive choice between standards, but few prominent cases ever permit researchers to garner a close look at behavior during deployment, as we get here. The $56 \mathrm{~K}$ modem fight had a well-publicized "standards war' for early adopters in Internet markets. Many contemporary press reports discuss how modem makers competed fiercely for adoption by the earliest choosers. Related, Shapiro and Varian (1999), pp 267-270, feature it prominently in their discussion of strategic behavior during standardization fights. Contemporary press accounts tend to cover announcements from firms, not the deployment in each local areas. No research has closely examined the deployment decision of service providers, as we do.

The competitive experience is also interesting because it motivated intervention from a government agency. At the time this experience appeared to be an example of "coordination failure." That is, there was a benefit to coordinating ISP's and consumers on a single standard as quickly as possible, but market actors failed to quickly standardize. Market participants expected that standardization would arise because it was in user interest. The popular standard would have more ISP's servicing it, which ensured consumers of high-quality, low hassle, low price service into the future. However, coordination did not arise 
in the first year of competition. Not only did the two technologies maintain relatively similar market shares, but overall sales to consumers and ISP's were well below what the two sides had hoped. Sales increased only after a government standard setting organization introduced a third incompatible standard as a new focal point for designs. The new standard quickly gained market acceptance and unified all designs. High industry sales followed.

Did competitive rivalry among ISPs contribute to the market's inability to coordinate on a standard unaided? In a final more speculative section of the paper, we argue that the standards war was prolonged by the market's structure, i.e., geographically dispersed decision making combined with the incentive to differentiate locally. This discussion directs further attention at issues not highlighted in the applied literature on standardization.

\section{Related Literature}

Our research goals are empirical. Yet, we lack prototypes for how to measure buyer and supplier behavior during a standards war. While user choice between alternatives plays a prominent role in many models of standardization, there are few empirical studies for characterizing its effect. Related, previous empirical work has focused on either the decision of whether to adopt a standard or not, or the decision of which standard to adopt, but has not dealt with decisions linking choice between two standards and non-adoption.

A few prior studies of competition in technology adoption provide us with general approaches for measuring competitive incentives. For instance, Klepper (2002) uses firm exit patterns, comparing very competitive and oligopolistic markets, to suggest a strong role for competition in cost-reducing technology adoption in a number of manufacturing industries. Genesove (1999) provides a study of the adoption of offset printing by newspapers and argues that firms in more competitive markets adopted earlier. Mulligan and Llinares (2003) show 
that ski-lifts were less likely to adopt quality-enhancing technology when local competitors had done so.

Though standards wars and the adoption of standards have received considerable attention in theoretical discussion, little empirical research examines decision making for standards. We borrow broadly from the general approach of empirical studies of technology adoption in network industries, though none explicitly provides us with a model for how to measure competitive behavior in a standards war. ${ }^{1}$ For example, Saloner and Shepard (1995) show the existence of network effects in bank service by showing that banks with more consumers adopt ATM networks earlier. Like our paper, they infer consumer behavior from observing decisions by firms in different locations. Gowrisankaran and Stavins (2002) and Ackerberg and Gowrisankaran (2003) look at the adoption of automated clearinghouse technology by banks. As with our paper, they exploit overlapping local geographic markets for important variation. However, they use a very different structural model of adoption incentives.

There are a few papers that consider the decision between two standards in horizontal competition. The approaches are quite different from ours, so we borrow broad motivation, but not a specific model. For example, Dranove and Gandal (2003) argue that the introduction of the DIVX standard slowed down the acceptance of DVD technology. Park (2000) and Ohashi (2000) study the standards war between VHS and Beta in the VCR market. Using market level data on quantities and prices, they focus on the role of installed base. Gandal, Kende and Rob (2000) study network effects between producers of compact disks and producers of CD players. They too find evidence of the interaction between software and hardware.

There also is a small literature on the behavior of ISPs. Closest to the present study is Augereau and Greenstein (2001), who examine the upgrade behavior by

\footnotetext{
${ }^{1}$ Shy (2001) provides an introduction and overview of both theoretical and empirical work on network effects.
} 
ISPs into higher speed technologies. The statistical model does not focus directly on the role of competitive incentives because the data are too coarse, allowing only for a comparison of ISPs located in "urban' and "rural' locations. They find faster upgrade behavior by ISPs in urban settings. Greenstein (2000) looks at whether ISPs differentiate from each other by offering services other than dial-up basic access, such as web design, network maintenance, hosting, or broadband to business. There is more differentiation among firms in urban settings, but, again, because the data are coarse so too is the inference. These papers can only speculate about why firms in different settings behave differently. The competitive setting might cause such differences across locations, but so could other factors.

In comparison to the previous literature this paper offers advances in several respects. First, we have access to very granular data about who competes with whom in ISP markets. This permits a direct measurement between the adoption decision of one competitor and all rivals. Second, we provide an empirical model of technology adoption in a standards war. We develop a non-cumbersome model that links decisions about whether to adopt with decisions about what to adopt. This provides insight about factors that shape decision making, such as competition and other local factors. Third, we provide an empirical method of a discrete decision while controlling for econometric issues of endogeneity, using the insights from the model of Seim (2002) to aggregate over the decisions of many other rivals. As such, the method generalizes to other types of decisions over discrete choices in rivalrous settings.

Finally, on a broad level we also build on a literature of cases studies of other industries that experienced events that looked like coordination failure to contemporaries. For example, Postrel (1990) associates the failure to adopt quadraphonic stereo with the presence of multiple, competing standards, which created confusion and delay downstream in distribution. Saloner (1989) attributes the failure to unify on a single standard of UNIX in the 1980s to proprietary in- 
terests in pursuing strategies that raise switching costs to work station users. Besen and Johnson (1986) and Rohlfs (2001) also relate a number of stories of delayed or failed adoption. For example, Besen and Johnson report that AM stereo required broadcasters and radio owners to be on the same standard, and broadcasts were delayed by the presence of multiple standards. As in our case, these are examples in which increasing the number of new choices plays a role.

We differ in that we highlight the role of differentiation in prolonging a standards war and leading to coordination failure. Existing theory would lead one to expect local "tipping" in a market with network effects. That, in turn, might give rise to either quick national unification or geographic balkanization, each market tipping in its own direction. Instead, neither of those theoretical possibilities occurred. There was no coordination between markets or within markets. Local competitive rivalry pushed in the opposite direction, towards local "splitting", when adoption occurred at all. We argue that this splitting fostered confusion about which technology would emerge as a standard - i.e., widespread splitting interfered with emergence of a technical focal point for market participants - which further deterred adoption decisions. In this sense our discussion, based on the theory in Rysman (2003a), is also a contribution because it differs from the common explanation. Rather, we observe behavior that appears consistent with inefficient incentives to differentiate across standards.

\section{Industry $^{2}$}

A modem allows a computer to send and receive data over a telephone line. Up until early 1997, 33.6K was the fastest modem available for use with analog telephone lines. A $33.6 \mathrm{~K}$ modem can send and receive 33.6 kilobits of data every second. Most modems connect to the Internet through a local telephone call to an Internet Service Provider. In 1997, about 93\% of the U.S. population

\footnotetext{
${ }^{2}$ A more in-depth discussion of these issues can be found in Rickard (1997a, 1997b, 1998).
} 
had access to a commercial ISP (Downes and Greenstein, 2002). As ISP's and telephone companies upgraded their connections to each other, it became technologically possible to raise modem speeds to $56 \mathrm{~K}$. 'With the concurrent development of the World Wide Web and the use of more graphics, demand for the Internet access and the importance of speed increased, providing demand for $56 \mathrm{~K}$ technology.

Players in the modem industry fell into two camps, either with US Robotics which developed the "X2" modem ${ }^{3}$ or with Rockwell Semiconductor which called their product "K56Flex." Both brought their product to market at essentially the same time, February 1997. Independent comparisons showed that the two standards worked equally well, although there was significant variability across and between standards depending on local connection characteristics. The two standards were incompatible in the sense that a consumer with one standard that connected to an ISP with the other standard would receive data at only 28 or $33 \mathrm{~K}$ (at most).

The ISP market was young in 1997, undergoing growth in new users and new entry in service providers. There were thousands of small firms with very small geographic focus, a few hundred firms with service beyond one city, and a few dozen with national or near-national footprints (Downes and Greenstein, 2002). Only the large firms had recognizable brands, such as AT\&T Worldnet or America On Line. Small and medium ISPs often offered other Internet services in addition to their dial-up service. Many took strategic positions as early movers into new technology and new services as a way to develop local customers bases and differentiate from their branded national ISP rivals (Greenstein, 2002).

The cost of the new modems depended on the purchaser. Modems for consumers were initially priced at around $\$ 200$, as compared to $33 \mathrm{~K}$ modems around

\footnotetext{
3 "X2" referred to the fact that $56=28 \mathrm{X} 2$. Although modems were up to $33 \mathrm{~K}$, much of the market was at $28 \mathrm{~K}$, and $33 \mathrm{~K}$ used the same basic technology at $28 \mathrm{~K}$.
} 
$\$ 100 .{ }^{4}$ For ISP's, the conversion depended on their technology. The typical installation required a Remote Access Server, a large server that came equipped with high quality modems and required T1 lines or ISDN lines. ${ }^{5}$ Such systems cost more than $\$ 50,000$ to install 50 ports. ${ }^{6}$ Many ISP's had already invested in Remote Access Servers and T1 or ISDN lines for some ports as they were also an efficient way to handle 33K modems. For those ISP's, they could simply upgrade their server. Doing so cost $\$ 50$ to $\$ 100$ per port and was sometimes offered for free as the standards battle intensified. The ability to upgrade depended on the server - USR servers could be upgraded only to X2, most other servers could be upgraded only to Flex. The result is that upgrade costs were much higher for some ISP's than others, and varied across standards. ISP's often used complicated combinations of servers and consumer-grade modems, so it is unlikely that rivals knew each other's technology exactly. We use these features to motivate our assumptions about unobserved terms in the structural model.

In what follows, we interpret observing ISP's evenly split across technologies as evidence of competition between ISP's. An alternative explanation may be endogenous responses by technology sponsors. That is, we may observe ISP's split across standards because a sponsor of a standard may lower prices in a location where it is failing. However we see no evidence that this occurred in the contemporary press and, as resale of equipment does not seem difficult, it may be hard to implement a strategy of geographic price discrimination.

\footnotetext{
${ }^{4}$ New PCs accounted for only a fraction of demand for faster modems in one year. Sales to the installed base of existing PC users through retail outlets was potentially much bigger. ${ }^{5} \mathrm{~T} 1$ and ISDN lines are fast, digital connections to the telephone network.

${ }^{6}$ Each connecting consumer requires 1 port. Allowing for the fact that consumers do not all connect at once meant that ISP's typically required 1 port for every 3 or 4 consumers. The number of ports that a typical ISP maintained at a given point-of-presence ranged from 50 to many thousands.
} 


\section{Data}

The data set used in this paper draws on a number of sources. The unit of analysis is the ISP and we use two directories of ISP's to create our data set. The first is from theDirectory. The list from theDirectory is meant to be comprehensive, including even the smallest ISP's. Importantly, theDirectory provides each phone number that each ISP can be contacted through, so we are able to determine each ISP's points of presence (POPs). However, theDirectory does not provide any other data on ISP's. In contrast, the Boardwatch directory gives information about the technologies that ISP's were using - in particular, which type of 56k an ISP adopted in October 1997 and July 1997 (before many large ISP's adopted and before the ITU was turned to in earnest). Also, Boardwatch lists whether an ISP had a T1 line and whether an ISP offered ISDN service to consumers. However, Boardwatch does not provide information on individual POPs. We merge the two data sets so we have both ISP technologies and their geographic locations.

This merge has a number of implications. First, we lose many observations from theDirectory because Boardwatch is less comprehensive. However, we believe that this loss is not a serious problem as Boardwatch contains data on the "most important" ISP's, and ISP's that are not in Boardwatch were unlikely to adopt $56 \mathrm{k}$. We assume the $56 \mathrm{k}$ adopters face a "competitive fringe" of $28 / 33 \mathrm{~K}$ firms to which these "lost firms" belong.

A second implication of the construction of our data set is that we observe only one adoption decision for each firm. We do not see if an ISP adopted one type of $56 \mathrm{k}$ in one market, the other in a second market, and chose not to adopt in a third market. Again, we believe this issue is not problematic as it appears that ISP's themselves treated the adoption decision as a single firm-wide decision. There are a few reasons for this to be the case. ISP's had an incentive to deliver uniform service throughout their market area, especially 
for clients who traveled. The choice of standard even seemed to become part of the image of the ISP. Also, competition among Rockwell and US Robotics led to the offering of exclusive contracts to ISP's. For instance, it is clear from press releases that national ISP's such as AT\&T and AOL, when they finally did adopt in November 1997, adopted only a signal standard and did so throughout their service areas.

Matching the October releases for each data set gives us 2233 ISP's. ${ }^{7}$ Next we determine markets for ISP's. Consumers almost always work with an ISP that is within the consumer's local telephone calling range. From CCMI, we obtain the Qtel data base which allows us to link telephone numbers to telephone switches, and switches to local calling plans. We assign each switch to the primary consumer local calling plan available from the incumbent telephone company. From this information, we can determine the switches that are served by each ISP, and the competitors that a consumer at each switch could potentially call. Also, we observe the zip code associated with each switch, which we use to add demographic data. We match switches to zip codes and counties and use zip code level demographics from the 2000 Decennial Census or (when zip code level data was unavailable) county level demographic data from the 1995 USA Counties CD-ROM. ISP's are spread over 9,076 switches, which creates 216,583 separate ISP-switch combinations. ${ }^{8}$

Using switches as a measure of size shows that the market is served by many small ISP's and a few very large ones. The mean number of switches served by an ISP is 96.8 but the distribution around the mean is very skewed. The median

\footnotetext{
${ }^{7}$ The original Boardwatch data set had 2653 observations, whereas theoriginal list from the Directory contained 5363 ISPs.

${ }^{8}$ Note the difference with Augereau and Greenstein (2001), who also examines ISDN and $56 \mathrm{k}$ modem adoption. That paper uses county boundaries as the definition for a geographic market, which identifies urban and rural locations, but not direct competitiors. In contrast here, the emphasis on the rivalrous behavior between potential adopters requires a definition of markets with greater granularity.
} 
ISP serves 16 switches, the 75 th percentile is 32 , and the largest 5 firms serve more than 4000 switches each. ${ }^{9}$ Note that there are more than 9,000 switches in the data set so no ISP covers the entire market. ${ }^{10}$

Table 1 shows adoption rates in July and October. Note that we construct the data using the October samples and simply append the October ISP's choices from July. That is, we ignore entry and exit over this 3 month period. Adoption by July was very low. While there was significant adoption by October, still only about half of ISP's had adopted. Moreover, the vast majority of non-adopting ISPs were large, so the percentage of customers served by $56 \mathrm{k}$ was much lower than a half. The slight lead enjoyed by X2 in July had turned into a slight lag by October. While very few firms adopt both technologies in July, they represent more than $15 \%$ of adopters in October. Note that having a T1 line is highly correlated with adoption. Among ISP's with T1 lines, $56 \%$ adopted $\mathrm{X} 2$ or Flex, whereas the adoption rate is $38 \%$ for those without a T1 line. We also observe whether firms offer ISDN lines to their consumers. ${ }^{11}$ Firms offering ISDN service adopted $56 \mathrm{~K} 66 \%$ of the time, whereas the adoption rate was only $29 \%$ among firms that did not offer ISDN service.

A simple way to look at the data is to take local calling areas as distinct markets. In fact, local calling areas do not create a partition of the United States - there are areas where switch A can make a local call to switch B and switch $\mathrm{B}$ can make a local call to $\mathrm{C}$ but $\mathrm{A}$ and $\mathrm{C}$ are not in the same local calling area. Hence, we create local calling areas by making some arbitrary

\footnotetext{
${ }^{9}$ Sixteen switches would be one or two local calling areas.

${ }^{10}$ There is no such thing as a truly national ISP as there are more then 19,000 switches in the United States. Most of these switches are served by ISP's, but by ISP's that we classify as being unlikely to adopt 56k: Downes and Greenstein (2002) show that the largest ISP's are present mostly in urban areas.

${ }^{11}$ Our dummy variable indicates if a firm offered ISDN service to consumers, not if a firm has an ISDN connection to the Internet. Firms that offer ISDN service to consumers require an ISDN connection to the Internet themselves. But many ISP's had ISDN connections without offering ISDN service to consumers.
} 


\begin{tabular}{|l|l|l|l|l|}
\hline & \multicolumn{2}{|c|}{ July 1997} & \multicolumn{2}{c|}{ October 1997} \\
\hline None & 1909 & $85.5 \%$ & 1136 & $50.9 \%$ \\
\hline X2 & 185 & 8.3 & 389 & 17.4 \\
\hline Flex & 112 & 5.0 & 523 & 23.4 \\
\hline Both & 27 & 1.2 & 185 & 8.3 \\
\hline
\end{tabular}

Table 1: Number and Percent of ISP's Adopting

assignments of switches to calling areas when a question arises. We find that this arbitrariness is not very problematic for looking at some simple summary statistics. ${ }^{12}$ Moreover, our final estimation procedure properly accounts for the overlap patterns.

Our method creates 2,298 local calling areas. Local calling areas have relatively few firms in each one. The average number of ISP's in a calling area is 15 with a standard deviation of 20.8 . However, there are 738 calling areas with only 1 ISP and the median number is only 3 . Table 2 gives average adoption rates by local calling area. Again, there are only a few adopters in each calling area. The average number of adopters in October 1997 is about 6 . Interestingly, although Flex leads X2 when tallied by ISP (as in Table 1), X2 leads Flex when tallied by locale (as in Table 2). ${ }^{13}$

\section{Simple Measures of Differentiation}

Our goal is to show that ISP's differentiated across standards instead of coordinated on one standard or the other. In this section, we present simple statistics that capture the spread of ISP's across the two standards within local calling

\footnotetext{
${ }^{12}$ Most of the issues arise in dense urban markets with many competitors. Medium to low density locations make up the bulk of the dataset and these are not problematic.

${ }^{13}$ Although this finding suggests that larger firms were more likely to adopt X2, we find the parameter on size (POPs) to be very similar across the two standards in our final estimation procedure.
} 


\begin{tabular}{|lll|}
\hline & $7 / 97$ & $10 / 97$ \\
\hline ISP's & 15.06 & 15.06 \\
Adopters & 0.99 & 5.98 \\
X2 & 0.59 & 2.58 \\
Flex & 0.22 & 1.99 \\
Both & 0.18 & 1.40 \\
\hline
\end{tabular}

Table 2: Averages by Local Calling Area

areas. This "first cut" of the data shows that ISP adoption is characterized by differentiation. This prediction is borne out in the more comprehensive empirical model presented in Section 6.

Our approach in this section is to compare the national adoption rate with the adoption rate in each local calling area. If the rates are close to the same, it suggests that ISP's were differentiating from each other. If local markets are characterized by agglomeration on one standard or the other, it suggests network effects were important.

Let $\left\{n_{i}^{0}, n_{i}^{A}, n_{i}^{B}, n_{i}^{A B}\right\}$ be the number of ISP's in market $i$ (a local calling area) that do not adopt, that adopt Flex, that adopt X2 and that adopt both. We start with a graphical presentation of our data. We calculate the number of adopters of only X2 as a percentage of the number of ISP's that adopt only one standard, ignoring markets with only one such firm. That is, we compute $n_{i}^{B} /\left(n_{i}^{A}+n_{i}^{B}\right)$ in each market where $n_{i}^{A}+n_{i}^{B}>1$. For now, we ignore firms that adopt both or neither standard $\left(n_{i}^{0}\right.$ and $\left.n_{i}^{A B}\right)$. The national adoption rate computed in this way is $58 \%$.

Figure 1 presents a histogram of adoption by calling area and captures much of what we try to show in this paper. The black bars represent the observed data. Figure 1 shows that most of the calling areas have between $50 \%$ and $80 \%$ adoption rates of $\mathrm{X} 2$, and there are very few calling areas with adoption 


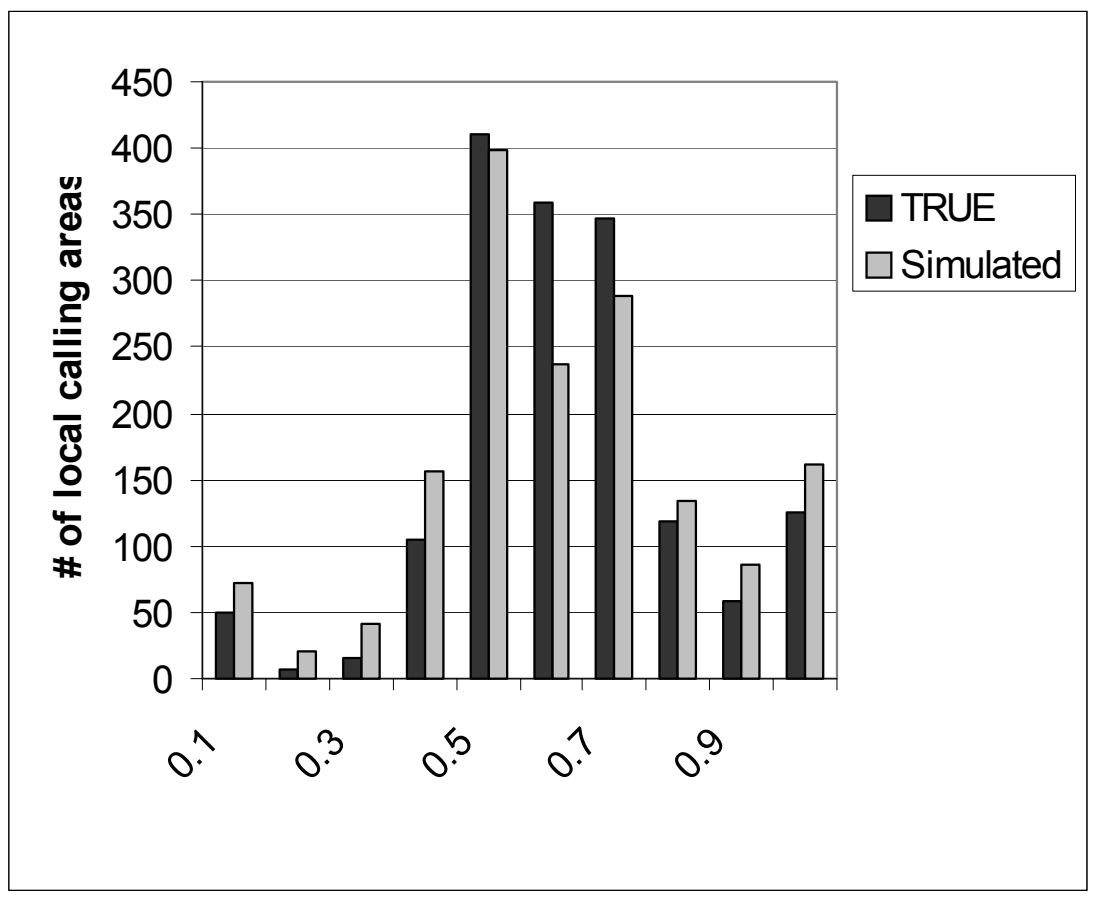

Figure 1: Percentage of ISP's adopting X2.

close to 0 or $100 \%$. As a point of comparison, we also calculate what would have happened if ISP's made independent random choices - that is, if $n_{i}^{A}+n_{i}^{B}$ firms in each market chose between $A$ and $B$ independently with probability $58 \%$. These results are represented by the gray bars. Figure 1 shows that independent random choice puts less weight in the center of the distribution and more weight on the tails. The black bars are higher than grey bars for the middle three bins and are lower than the grey bars for the outer seven. Figure 1 suggests that differentiation (even splits between each standard within each locale) characterizes this data, relative to independent random choice or coordination.

In order to statistically test whether the hypothesis of independent random choice can be rejected, we use the dartboard index of Ellison and Glaeser 
(1997). ${ }^{14}$ We compute the index for each calling area separately and take an unweighted national average. The dartboard index is positive if ISP's are more coordinated on a single standard than we would expect from independent random choice and is negative if they are more differentiated. The dartboard index accounts for the fact that we have small sample sizes within locales ${ }^{15}$. Under the null hypothesis of independent random choice, the dartboard index is 0 and we use Monte Carlo techniques to generate a standard deviation.

Results appear in Table 3. In Row 1, we consider ISP's that adopt only one standard and markets with at least two such ISP's. In the terminology of Ellison and Glaeser, firms can be in one of two states $A$ and $B$ and we check if $n_{i}^{A}$ and $n_{i}^{B}$ show evidence of agglomeration, dispersion or independent allocation. The average dartboard index across 1595 markets is -0.085 . Under the null, it would be 0 with a standard error of 0.012 , so the null hypothesis can be rejected in favor of differentiation. Row 2 includes firms that adopt both standards as if they adopted X2. That is, the two states are $\{A\}$ and $\{B, A B\}$ and we compute the dartboard index on $n_{i}^{A}$ and $\left(n_{i}^{B}+n_{i}^{A B}\right)$. The results do not change. We may also be interested in the distinction between adopting and not adopting, ignoring the choice of standard. We consider the case where firms can be in one of the two states $\{A, B, A B\}$ or $\{0\}$ and compare $\left(n_{i}^{A}+n_{i}^{B}+n_{i}^{A B}\right)$ to $n_{i}^{0}$. Row 3 shows that for this case, the data appears coordinated (in each case, we include only markets with at least 2 ISP's satisfying the relevant criteria). That is, most markets are characterized by very high adoption or very little

\footnotetext{
${ }^{14}$ Ellison and Glaeser's approach has the advantage over more standard tests such as the Pearson Goodness of Fit test that it not only rejects independent random choice but also tells the researcher whether the rejection is due to disperse or agglomerated data. See Rysman and Greenstein (2003) for further discussion and an alternative approach.

${ }^{15}$ The dartboard index is essentially a Gini coefficient for the distribution of ISPs over each standard. If there are a small number of ISP's in a locale, we expect the Gini to be greater then zero regardless of how they make decisions, so the dartboard index modifies the Gini coefficient by the Herfindahl of the decision making agents to get a value that has an expected value of zero under the null of independent random choice.
} 
Table 3: Dartboard Test for Differentiation

\begin{tabular}{|l|l|l|l|l|}
\hline Description & index & std dev & t-statistic & Markets \\
\hline Adopt only X2 vs. Adopt only Flex & -0.085 & 0.012 & -6.78 & 1595 \\
Adopt X2 or Both vs. Adopt only Flex & -0.038 & 0.012 & -3.12 & 1698 \\
Adopt vs. Not Adopt & 0.034 & 0.010 & 3.32 & 2200 \\
\hline
\end{tabular}

adoption, and there are few markets in between. This result may be explained by local rivalry or local market demand (i.e., local demographic information), and suggests the importance of controlling for local conditions in more stringent tests.

Another way to look at the issue of differentiation across standards is to exploit the dynamic aspect of the data. We can compare choices made up to July 1997 to choices made afterwards. The results appear in Table 4. This table shows that there were 1029 local calling areas where there was at least one adopter by July. The columns refer to whether or not X2 was leading in that calling area by July 1997. On the row is the number of calling areas where more ISP's adopted X2 than Flex in the July-October window. For instance, the table shows that of the 686 calling areas where X2 led in July, Flex tied or led X2 from over the next 3 months in more than half the calling areas. The numbers are more striking for calling areas where Flex led in July. Of these 152 calling areas, there are 3 times as many locales where X2 led for July - October as there are those where Flex led. These numbers suggest that ISP's that observed one standard obtain a lead did not continue to adopt that standard.

These statistics characterized the data by differentiation, not coordination. They are strongly suggestive of the results we find in the full empirical model in Section 6. 
Table 4: Adoption in July 1997 versus adoption over the next 3 months

\begin{tabular}{|l|l|l|l|l|l|}
\hline \multirow{2}{*}{} & & \multicolumn{4}{|c|}{ Adoption by $7 / 97$} \\
\cline { 3 - 6 } Adoption & \multirow{3}{*}{ X2 Leads for 7-10 } & X2>Flex & Tied & Flex $>$ X2 & Total \\
\cline { 3 - 6 } Betw. 7/97 & Tie & 178 & 54 & 65 & 297 \\
and 10/97 & Flex Leads & 183 & 58 & 20 & 261 \\
& Total Calling Areas & 686 & 191 & 152 & 1029 \\
\hline
\end{tabular}

\section{Estimation}

While the results in Section 5 are suggestive of an industry characterized by differentiation, the methodology ignores important features of the industry. In particular, ISP's make a single adoption choice at all of their points-of-presence so local calling areas are not independent markets. Even defining local callings areas involves some arbitrariness. Furthermore, the methodology above does not exploit demographic data and is difficult to interpret when we recognize that some firms adopt both standards. The main econometric model addresses all of these features.

\subsection{Model}

In our econometric model, ISP's that offer 33K service at a POP decide whether or not to offer $56 \mathrm{k}$ service on X2, Flex, both or neither. In this sense, the model is like an entry game into two markets, X2 and Flex, in which we observe potential entrants, as in Berry (1992). Following the theoretical model in Rysman (2003a), we model the entry game as one of imperfect information, where we allow for firms to observe their own unobservable draws but not those of their competitors. In this regard, we follow the estimation methodology of Seim (2002). ${ }^{16}$

\footnotetext{
${ }^{16}$ Several recent papers have exploited this assumption to develop two-stage estimators of discrete (and dynamic) games. See Pakes, Ostrovsky and Berry (2003), Agguiregabiria and
} 
Our estimation model is as follows. There are $n$ firms and $I$ locations. Locations in the model are equivalent to switches in the data. ${ }^{17}$ The set of locations in which firm $j$ appears is $\vartheta_{j}$. We compute $\vartheta_{j}$ to be the set of all switches from which ISP $j$ can be contacted by a local telephone call. A firm may adopt either standard $s$, adopt both or not adopt, but the firm makes the same adoption decision in every location. The number of firms that have adopted technology $s$ at location $i$ besides $j$ is $n_{i}^{s}$, where $s$ can be equal to $\{0, A, B, A B\}$ (none, Flex, X2, and both). The potential adopters at a switch are identified by finding all ISP's that can be contacted by a local telephone call.

Firms draw a cost shock $\varepsilon_{j}^{s}$ for each standard. Firms observe their own draws of $\varepsilon_{j}^{s}$ but not those of their competitors. The shocks represent the adoption cost for the firm. One source of these costs may be the combination of servers, consumer grade modems and digital connections a firm has which, as argued earlier, affected the adoption cost of $56 \mathrm{~K}$ and were arguably not well known to their competitors. Because of this incomplete information, we search for a Perfect Bayesian Equilibrium. ${ }^{18}$ The expected profit from adopting $A$ or $B$ in location $i$ for firm $j$ is:

$$
E\left[\pi_{i j}^{s}\right]=x_{i}^{l} \beta_{1}+x_{j}^{f} \beta_{2}+E\left[\psi_{1}\left(n_{i}^{s}+1\right)+\psi_{2} n_{i}^{A B} \mid \mathbf{X}, \theta\right] \quad s=A, B
$$

The "+1" in the parenthesis accounts for the effect of firm $j$ on profitability in Mira (2002) and Pesendorfer and Schmidt-Dengler (2003).

${ }^{17}$ In this section, location $i$ refers to a switch whereas in Section 5 , location $i$ referred to a local calling area.

${ }^{18}$ Our solution concept is equivalent to a Quantal Response Equilibrium. See McKelvey and Palfrey (1995), and Haile, Hortascu and Kosenock (2003) for a discussion of its empirical content. 
location $i$. Average profit for firm $j$ from adopting standard $s$ is: $^{19}$

$$
E\left[\Pi_{j}^{s}\right]=\frac{1}{I} \sum_{i \in \vartheta_{j}} E\left[\pi_{i j}^{s}\right]+\varepsilon_{j}^{s}, s=A, B
$$

We assume the $33 \mathrm{~K}$ market is competitive everywhere and normalize profits from non-adoption to zero. The profits from adopting both standards is simply the sum of adopting each standard. Therefore:

$$
E\left[\Pi_{j}^{0}\right]=0 \quad E\left[\Pi_{j}^{A B}\right]=E\left[\Pi_{j}^{A}\right]+E\left[\Pi_{j}^{B}\right]
$$

The firm chooses the option with the highest expected payoff. ${ }^{20}$ The vectors $x_{i}^{l}$ and $x_{j}^{f}$ capture location specific and firm specific variables. The parameters $\psi_{i}$ capture the effect of competition on profits. The matrix $\mathbf{X}$ contains all exogenous variables, including all values of $x_{i}^{l}, x_{j}^{f}$ and adoption decisions by firms in previous periods. The variable $\varepsilon_{j}^{s}$ is a random fixed cost for standard $s$ unobserved by the researcher or other firms. We assume that $\left[\varepsilon_{j}^{A} \varepsilon_{j}^{B}\right]$ is distributed iid according the standard bivariate normal distribution with correlation parameter $\rho .^{21}$ The parameters $\theta=\left\{\beta_{1}, \beta_{2}, \psi_{1}, \psi_{2}, \rho\right\}$ are to be estimated. In practice, we allow them to differ for each standard. Our goal is to check whether $\psi_{1}<0$, which implies that firms prefer differentiation to agglomeration.

A widely recognized problem in the empirical literature on entry games is the potentially endogenous determination of the number of competitors. A high

\footnotetext{
${ }^{19}$ Using average profit is equivalent to using total profit and imposing a particular form of heteroskedasticity.

${ }^{20}$ Note that in describing profits, we have left off any terms representing value in the future. We do not try to solve the full dynamic game and in this sense, the parameters we estimate capture both the flow profit from their associated variable and the expected future profit. In addition, they may capture the fact that waiting has different values to different firms, depending on future expectations.

${ }^{21}$ An alternative approach would be to have firms that adopt both standards recieve a (possibly negative) award due to economies of scope. It is difficult to distinguish between economies of scope and a correlation in errors, which Manski (1998) terms the reflection problem. We take $\rho$ to capture both correlation in errors and economies of scope.
} 
draw of $\varepsilon_{j}^{s}$ might be due to the fact the location is desirable. In that case, $n_{i}^{s}$ will also be high. Conversely, a high draw of $\varepsilon_{j}^{s}$ might suggest that $n_{i}^{s}$ is small because firm $j$ will almost surely enter. However, as shown in Seim (2002), modelling the entry game as one of imperfect information addresses this problem. In this case, firms make their decision based not on $n_{i}^{s}$ but on $E\left[n_{i}^{s} \mid \mathbf{X}, \boldsymbol{\theta}\right]$, which depends only on exogenous variables. We discuss computation of $E\left[n_{i}^{s} \mid \mathbf{X}, \boldsymbol{\theta}\right]$ below.

Integrating over $\varepsilon_{j}^{A}$ and $\varepsilon_{j}^{B}$, the implied adoption probabilities for firms that did not adopt in July are:

$$
\begin{aligned}
P_{j N} & =\operatorname{Prob}\left(d_{j}=N\right)=\Phi\left(-\Pi_{j}^{A},-\Pi_{j}^{B}, \rho\right) \\
P_{j s} & =\operatorname{Prob}\left(d_{j}=s\right)=\Phi\left(\Pi_{j}^{s},-\Pi_{j}^{-s},-\rho\right) \quad s=A, B \\
P_{j A B} & =\operatorname{Prob}\left(d_{j}=A B\right)=\Phi\left(\Pi_{j}^{A}, \Pi_{j}^{B}, \rho\right)
\end{aligned}
$$

Here, $d_{j}$ is the decision of firm $j$ and $\Phi()$ is the bivariate normal CDF with correlation parameter $\rho$. For a firm that adopted one technology in July, the probability of adopting the other in October is:

$$
P_{j s}=\operatorname{Prob}\left(E\left[\Pi_{j}^{s}\right]>-\varepsilon_{j}^{s} \mid E\left[\Pi_{j}^{-s}\right]>-\varepsilon_{j}^{-s}\right)
$$

We compute this integral by Gaussian quadrature. The likelihood function for observing the $n$ decisions $d_{1}, \ldots, d_{n}$ is:

$$
L\left(d_{1}, \ldots, d_{n}, \mathbf{X}, \theta\right)=\prod_{j=1}^{n} P_{j d_{j}}
$$

In order to compute $E\left[n_{i}^{s} \mid \mathbf{X}, \boldsymbol{\theta}\right]$, we use the following relation: The expected number of firms making choice $s$ at location $i$ can be divided into the the number that chose $s$ previously (by July 1997) $n_{i}^{s, p r}$ and the number choosing currently $n_{i}^{s, c u}$, the expectation of which depends on the adoption probabilities. Let $\Upsilon(i)$ be the set of firms present in location $i$ :

$$
E\left[n_{i}^{s} \mid \mathbf{X}, \boldsymbol{\theta}\right]=n_{i}^{s, p r}+E\left[n_{i}^{s, c u} \mid \mathbf{X}, \theta\right]=n_{i}^{s, p r}+\sum_{k \in \Upsilon(i)} P_{k s}
$$


In order to calculate the term $E\left[\psi_{1} n_{i}^{s}+\psi_{2} n_{i}^{A B} \mid \mathbf{X}, \theta\right]$, we follow Seim (2002) and exploit the fact that the system of equations 1, 2 and 4 form a fixed point equation, solved by the $n \times 4$ matrix of adoption probabilities $\mathbf{P}$, with element $P_{j s}$. For any given set of parameters $\theta$, the first step in solving for $E\left[\psi_{1} n_{i}^{s}+\right.$ $\left.\psi_{2} n_{i}^{A B} \mid \mathbf{X}, \theta\right]$ is to compute $E\left[\Pi_{j}^{s}\right]^{0}$, the value of $E\left[\Pi_{j}^{s}\right]$ assuming no firms adopt. Doing so gives probabilities of adoption $\mathbf{P}^{0}$ that we use to create an initial guess, $E\left[\psi_{1} n_{i}^{s}+\psi_{2} n_{i}^{A B}\right]^{0}$. Using this value, we calculate $E\left[\Pi_{j}^{s}\right]^{1}$, which generates a new set of adoption probabilities $\mathbf{P}^{1}$ and a new value $E\left[\psi_{1} n_{i}^{s}+\psi_{2} n_{i}^{A B}\right]^{1}$. We continue iterating in this way as described by Seim (2002) until there is convergence, thereby finding a fixed point in adoption probabilities for the system of bestresponse functions. ${ }^{22}$ The appendix discusses the computation of the fixed point in greater detail.

A weakness of our approach is that it does not guarantee that there is a unique equilibrium. There may be multiple matrices $\mathbf{P}$ that solve the system of equations above. In this model, this can occur for two reasons. The first is associated with entry models and can occur if $\psi_{i}<0$. Intuitively, there could be an equilibrium where ISP 1 is expected to enter with high probability and ISP 2 with low, and another equilibrium where the opposite is true. The second is associated with network effects and can occur if $\psi_{i}>0$. In this case, there can be an equilibrium where most firms adopt and one where few firms adopt. Our methodology requires either a unique equilibrium or an equilibrium selection mechanism. The methodology relies on asymmetry in the data to find uniqueness. For instance, while one might expect that there are multiple equilibria between two symmetric firms, it would be less likely between a very large firm and a very small firm. ${ }^{23}$ We further discuss this issue with the results.

\footnotetext{
${ }^{22}$ The adoption probabilities $P_{j N}, P_{j A}, P_{j B}$, and $P_{j 2}$ can be defined by only 2 cut-offs, so in fact, the solution to our fixed point system is an $n \times 2$ matrix.

${ }^{23} \mathrm{It}$ is possible for there to be multiple equilibria in expectations that are so similar that their difference is not important empirically.
} 


\subsection{Identification}

This methodology creates a variable $E\left[\psi_{1} n_{i}^{s}+\psi_{2} n_{i}^{A B} \mid \mathbf{X}, \theta\right]$ that nicely captures our intuition for identification. As with standard instrumenting techniques, it is important that there are variables that affect the expected number of adopters that $j$ faces but that do not otherwise affect the decision of firm $j$. In this sense the overlapping calling areas of different ISPs acts as a virtue. The relationship between firms that provides the best identifying power would be a firm that is completely overlapped by another firm, where the overlapping firm is also present in many other locations. Then, the variable $E\left[\psi_{1} n_{i}^{s}+\psi_{2} n_{i}^{A B} \mid \mathbf{X}, \theta\right]$ for the small firm depends on a large amount of demographic data that do not otherwise appear in the decision of the firm. Cases where two firms completely overlap but do not appear in many other locations should not provide strong identification as the same demographic data that affect $E\left[\psi_{1} n_{i}^{s}+\psi_{2} n_{i}^{A B} \mid \mathbf{X}, \theta\right]$ also appear directly in the firms' decisions. Similarly, firms that appear in many different locations but barely overlap with each other should not provide much identification as these firms barely affect $E\left[\psi_{1} n_{i}^{s}+\psi_{2} n_{i}^{A B} \mid \mathbf{X}, \theta\right]$ for each other.

Other papers, such as Gowrisankaran and Stavins (2002), have used the intuition that the decisions of geographically large firms can be thought of as exogenous to the decisions of small firms. Our intuition is similar, although we capture exogeneity in a more continuous way - the decision of a large firm may be exogenous to a medium-sized firm and the decision of large and medium firms may be exogenous to that of a small firm. With our methodology, we do not have to make an a priori decision about which firms are exogenous to which. A drawback is that we do not use the actual decision of large firms as an exogenous variable, only the prediction of those decisions based on explanatory variables.

Further important exogenous variation comes from the characteristics of firms, such as their size and the presence of a digital connection. A final but 
potentially important form of exogenous variation comes from decisions made by firms in July 1997. The above mentioned forms of exogenous variation differ across firms but not across standards. Without an exogenous variable that varied by standard, we would not be able to predict that firms are more likely to choose one standard or another. Adoption choices made three months earlier provide this form of variation. ${ }^{24}$

\section{$7 \quad$ Results}

Table 5 presents the main results. The first two columns present coefficient estimates and standard errors from estimating Equation 1 using the observed values of $n_{i}^{s}$ instead of expected values. It is equivalent to a bivariate probit model predicting adoption of Flex and X2. Relative to the histogram in Figure 1, this model controls for ISP decision-making across multiple markets, for demographics and ISP characteristics and for the exact competitive environment resulting from the pattern of local calling areas. This model does not explicitly correct for endogeneity of choices by competing firms. ${ }^{25}$ We present these results as an interim step towards our true model and to evaluate the role of the instruments in the true model.

However, we begin our discussion with the second column, which presents results correcting for endogeneity according to the model of imperfect information described above. The result of primary interest is the first row, which measures the effect of the number of competitors on standard $s$ on the proba-

\footnotetext{
${ }^{24} \mathrm{~A}$ common criticism of the entry literature is that it models dynamic processes as simultaneous games. While we are subject to this criticism as well, the effects are mitigated by the fact that we model only a 3 month process as a simultaneous game.

${ }^{25}$ Note that under the assymetric information assumptions made in the model, the realized number of entrants $n_{i}^{s}$ is exogenous. Furthermore, under the assumption that $n_{i}^{s}-E\left[n_{i}^{s} \mid \mathbf{X}, \theta\right]$ is normal, this difference is absorbed by the probit error and the model using the observed $n_{i}^{s}$ in place of $E\left[n_{i}^{s} \mid \mathbf{X}, \theta\right]$ is actually a consistent estimator for the true model.
} 
bility of adopting standard $s$. In the first row of column 2 , the effect is negative and significant, implying the incentive to differentiate outweighed the incentive to coordinate. The effect is reasonable and important. Doubling the number of competitors adopting Flex reduces the probability of adopting Flex for a given firm by 4.3 percentage points, a $13.9 \%$ change. These numbers are evaluated at means in the data, where the average number of competitors on Flex is 5.78 and the average number of competitors on $\mathrm{X} 2$ is 7.02 .

The coefficient on the number of firms adopting both standards is positive but insignificant. We provide an interpretation for this result below. We see that ISP characteristics are important predictors of adoption. Firms that have digital connections to the Internet are much more likely to adopt $56 \mathrm{~K} .{ }^{26}$ Larger firms, as measured by the number of switches a firms serves, are also more likely to adopt both standards. This effect is estimated to be quadratic, probably driven by the fact that the very largest firms in this data set do not adopt.

Under the assumption that the $33 \mathrm{~K}$ market is competitive in all markets, the number of ISP's in a market should not matter directly. However, we include the log of the number of ISP's at a switch as a proxy for both the consumer population at a switch (which we do not otherwise observe) and that populations' preference for technology. This parameter is positive and significant. We also include a dummy for whether that standard had a lead at this switch in July, 1997. This parameter is not significant. It may be that there was simply very little variation in this variable, as suggested by the Table 2 . We also include the number Internet backbone providers at a switch. These firms often leased modem banks to ISP's indicating it was particularly easy to adopt in these locations. As expected, this coefficient is positive and significant.

Demographic characteristics do not appear to be very important as only a few are estimated to be significant. Surprisingly, the percentage of the pop-

\footnotetext{
${ }^{26}$ As above, digital indicates the firm has a T1 line or offers ISDN service to customers, but could be 0 if a firm has ISDN lines but does not offer ISDN service to consumers.
} 


\begin{tabular}{|c|c|c|c|c|}
\hline & \multicolumn{2}{|c|}{$\begin{array}{c}\text { Without endogeneity } \\
\text { correction }\end{array}$} & \multicolumn{2}{|c|}{$\begin{array}{l}\text { With endogeneity } \\
\text { correction }\end{array}$} \\
\hline Firms on same standard & -0.094 & $(0.007)$ & -0.050 & $(0.013)$ \\
\hline Firms on both standards & 0.121 & $(0.012)$ & 0.037 & $(0.031)$ \\
\hline constant & -1.386 & $(0.726)$ & -2.287 & (0.744) \\
\hline In POP's & 0.149 & $(0.055)$ & 0.107 & $(0.058)$ \\
\hline In POP's sq & -0.012 & $(0.006)$ & -0.010 & $(0.006)$ \\
\hline digital & 0.624 & $(0.054)$ & 0.659 & $(0.055)$ \\
\hline In \# of ISP's & 0.059 & $(0.047)$ & 0.122 & $(0.054)$ \\
\hline Lead in July & -0.047 & $(0.162)$ & 0.091 & $(0.164)$ \\
\hline bone providers & 0.0008 & $(0.002)$ & 0.005 & $(0.002)$ \\
\hline ('000's) & 0.004 & $(0.004)$ & 0.006 & $(0.005)$ \\
\hline$\%$ urban pop & -0.009 & $(0.168)$ & 0.041 & $(0.173)$ \\
\hline$\%$ pop in MSA/PMSA & 0.192 & $(0.211)$ & -0.045 & $(0.222)$ \\
\hline est./capita & 12.714 & $(6.960)$ & 9.155 & (7.281) \\
\hline$\%$ college grads & -5.630 & $(1.690)$ & -3.803 & (1.794) \\
\hline population growth & -0.542 & $(0.649)$ & 0.347 & $(0.657)$ \\
\hline f county $5 \mathrm{yr}$ & 2.021 & $(0.642)$ & 1.520 & $(0.680)$ \\
\hline \# home permits/cap. & 3.83 & (3.790) & -4.253 & (3.786) \\
\hline rho & -0.271 & $(0.046)$ & -0.103 & $(0.038)$ \\
\hline $\begin{array}{l}\text { mean log likelihood } \\
\text { observations }\end{array}$ & \multicolumn{2}{|c|}{$\begin{array}{l}-0.915 \\
2206\end{array}$} & \multicolumn{2}{|c|}{$\begin{array}{l}-0.954 \\
2206\end{array}$} \\
\hline
\end{tabular}

Notes: Column 1 assumes all explanatory variables are exogenous.

Column 2 corrects for endogeneity in the first two variables.

Standard errors are in parenthesis.

Table 5: Main Results 
ulation that graduated from college is negative. As expected, the percentage of the population living in a different county five years previous (a proxy for county growth) is positive and significant. A test of joint insignificance for the demographic variables can be rejected, suggesting that the demographics still play a role in identifying the parameters on endogenous variables despite their individually imprecise estimates.

The parameter $\rho$ is estimated to be negative, implying that firms that adopt one technology are less likely to adopt the other. This may reflect a number of issues, such as diseconomies of scope or a negative correlation in unobserved shocks.

Returning to the first column in Table 5 (which does not control for endogeneity), we see that the number of firms on the same standard has a negative and significant impact on adopting of that standard. Most of the results are similar across the two models, although the number of ISP's in a market is insignificant in column 1. The parameter on the number of firms adopting both standards is positive and significant in column 1 . We interpret this result as reflecting consumer adoption patterns. If some areas have a strong preference for new technology, we might expect many firms to adopt both technologies in those markets. If we do not otherwise control for these consumer actions, we will estimate a positive coefficient on the effect of firms that adopt both. This "endogeneity" interpretation is supported by column 2, as the effect turns insignificant when we estimate the structural parameter.

Overall, we conclude that the incentive to differentiate outweighed the incentive to coordinate in this market. This result is surprising in these tests because of the size of the markets. Finding differentiation in favor of independent random choice is more difficult in large markets as the two hypothesis have similar predictions as the number of agents gets large. In the histogram in Figure 1, the level of observation is a market and the average number of adopters in a market is 5.98. However, the level of observation in these regressions is the ISP 
and ISP's face on average 17.1 adopters. One need only a few large markets to achieve this dichotomy. Even so, the results reject independent random choice by ISP's in favor of differentiation by ISP's.

We perform a number of robustness tests. An important component for our story is that the two technologies are functionally identical. We test for that by testing the hypothesis that the parameters are equal across the two standards. Table 6 presents results in which parameters are allowed to differ across the two technologies. The first set of results assume that $n_{i}^{s}$ is exogenous and the second correct for endogeneity. Both the likelihood ratio test and the Wald test reject the hypothesis of joint equality of each parameter row in both models. However, we present p-values for variable-by-variable Wald tests and these are more supportive. For these independent tests, we see that the hypothesis of equality cannot be rejected at a $95 \%$ or even $90 \%$ level of confidence for any variable for the model controlling for endogeneity. Even when not controlling for endogeneity, the hypothesis of individual equality can be rejected at a $95 \%$ level of confidence for only three variables. Furthermore, variables look broadly similar across the equations. Given these results and the strong institutional support for the symmetry of the two technologies, we conclude that restricting the parameters to be the same across technologies is reasonable.

Also, note that the variable measuring the effect of the number of firms on the same standard is negative for both technologies in both models. However, it is insignificant in one of the cases: X2 in the model correcting for endogeneity. Why is this result insignificant here but significant when we restrict parameters to be the same across technologies? One reason is that allowing the parameters on endogenous variables to differ across standards means we need an instrument that varies across standards. The fact that we get inconclusive results in this circumstance suggests that our instrument, adoption in July, does not provide the necessary variation to identify all of these parameters. Indeed, note that the dummy for the standard having a lead in July turns out to be insignificant 
throughout the results.

We present another set of robustness results in Table 7 . In the first column, we include the number of firms on the other standard as a third endogenous variable. If consumer adoption were adequately controlled for, the number of firms on the other standard might be reasonably expected to have no impact. However, in our circumstance, it may reflect consumer adoption. In fact, we find the new variable is statistically insignificant. Otherwise, we find similar results to those reported in Table 5. Note that the variable of primary interest, the parameter on the number of firms in the same standard, is again negative but less precisely estimated: the t-statistic is 1.957 .

As a final robustness test, we check if our results are driven by the firms that adopt one standard in July. We re-estimate the model in column 2 of Table 5 but construct the likelihood value from only the 1909 observations that did not adopt at all in July. ${ }^{27}$ The results appear in column 2 of Table 7 . The results are very similar to those estimated using all of the observations. The most striking difference is the change in the estimate of $\rho$. Here, $\rho$ is estimated to be much closer to zero and insignificant. This result suggests that ISP's that adopted one technology in July were less likely to adopt both in October than ISP's that did not adopt at all in July. As the results of primary interest do not change in this model, we do not further explore this issue here.

As discussed above, it is necessary that there be a unique equilibria or we specify an equilibrium selection mechanism. For models that control for endogeneity, we search for multiple equilibria at the estimated parameters. We do this by using different starting values in our fixed point algorithm that finds equilibrium adoption probabilities. For instance, we start the algorithm at zero adoption for all firms, certain adoption of $\mathrm{A}$ for all firms, certain adoption uni-

\footnotetext{
${ }^{27}$ The model of imperfect information requires us to make predictions about the adoption of the remaining technology for firms that adopt one standard in July. The estimated parameters are applied to those firms in this sense.
} 


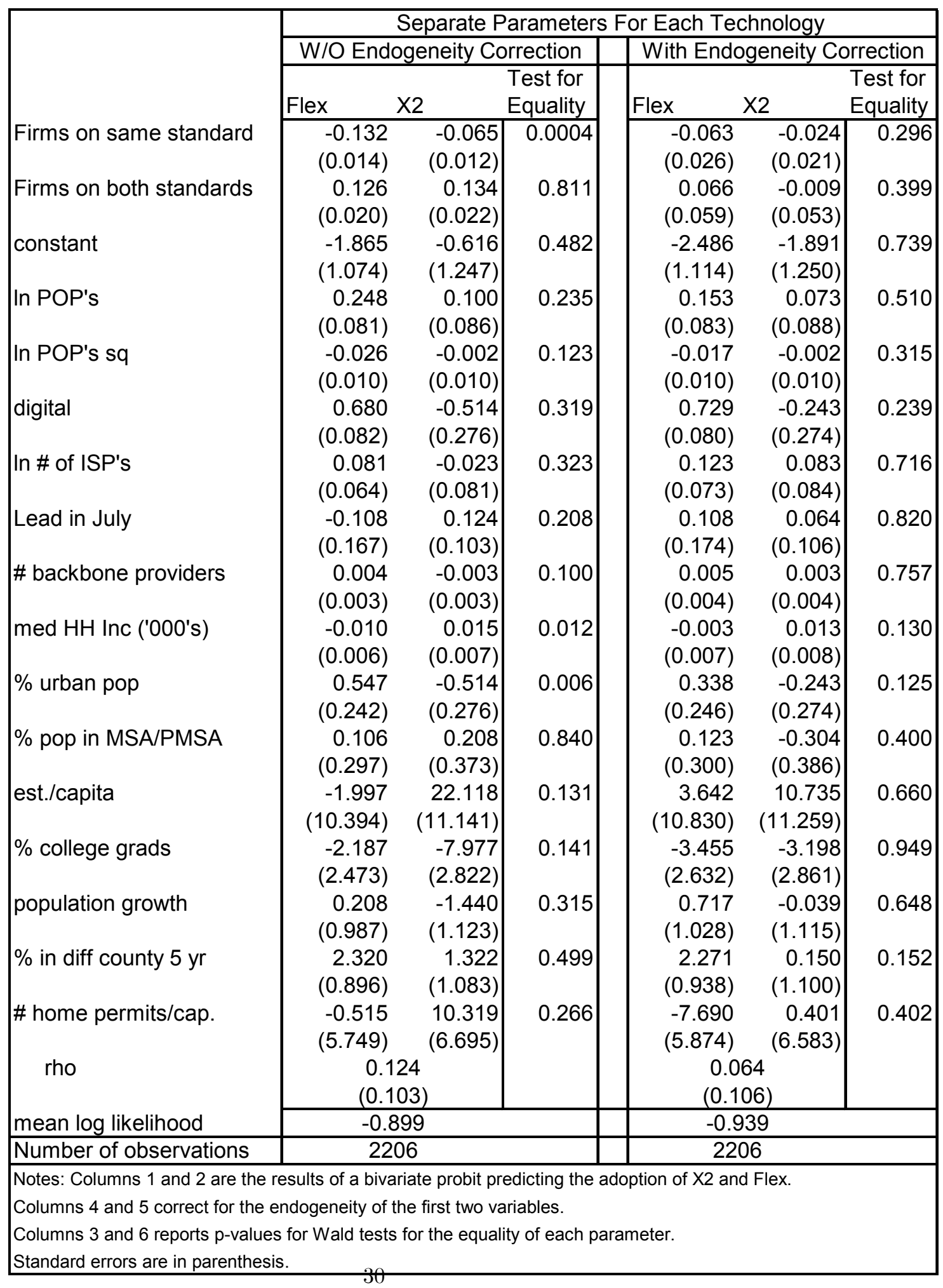

Table 6: Results from allowing parameters to differ across technologies. 


\begin{tabular}{|c|c|c|c|c|}
\hline & \multicolumn{2}{|c|}{$\begin{array}{c}\text { Three endogenous } \\
\text { variables }\end{array}$} & \multicolumn{2}{|c|}{$\begin{array}{c}\text { Only firms that have } \\
\text { not adoted in July }\end{array}$} \\
\hline Firms on same standard & -0.137 & $(0.070)$ & -0.058 & $(0.016)$ \\
\hline Firms on both standards & 0.027 & $(0.032)$ & 0.043 & $(0.032)$ \\
\hline Firms on other standard & 0.094 & $(0.071)$ & & \\
\hline constant & -2.051 & $(0.759)$ & -1.967 & $(0.808)$ \\
\hline In POP's & 0.111 & $(0.058)$ & 0.140 & $(0.063)$ \\
\hline In POP's sq & -0.011 & $(0.006)$ & -0.013 & $(0.007)$ \\
\hline digital & 0.663 & $(0.055)$ & 0.664 & $(0.058)$ \\
\hline In \# of ISP's & 0.106 & $(0.053)$ & 0.114 & $(0.057)$ \\
\hline Lead in July & 0.261 & $(0.195)$ & 0.086 & $(0.169)$ \\
\hline \# backbone providers & 0.0044 & $(0.002)$ & 0.004 & $(0.002)$ \\
\hline med HH Inc ('000's) & 0.006 & $(0.005)$ & 0.009 & $(0.005)$ \\
\hline$\%$ urban pop & 0.041 & $(0.174)$ & 0.137 & $(0.186)$ \\
\hline$\%$ pop in MSA/PMSA & -0.040 & $(0.222)$ & -0.105 & $(0.241)$ \\
\hline est./capita & 8.855 & (7.346) & 8.369 & (7.811) \\
\hline$\%$ college grads & -3.969 & $(1.808)$ & -4.920 & (1.951) \\
\hline population growth & 0.216 & $(0.664)$ & -0.022 & $(0.709)$ \\
\hline$\%$ in diff county $5 \mathrm{yr}$ & 1.548 & $(0.682)$ & 1.645 & $(0.730)$ \\
\hline \# home permits/cap. & -3.741 & (3.839) & -3.287 & (4.103) \\
\hline rho & -0.097 & $(0.038)$ & -0.015 & $(0.045)$ \\
\hline $\begin{array}{l}\text { mean log likelihood } \\
\text { observations }\end{array}$ & \multicolumn{2}{|c|}{$\begin{array}{c}-0.953 \\
2206 \\
\end{array}$} & \multicolumn{2}{|c|}{$\begin{array}{c}-1.035 \\
1909 \\
\end{array}$} \\
\hline
\end{tabular}

Notes: Column 1 treats the first three variables as endogenous

Column 2 uses only observations that did not adopt at all in July

Standard errors are in parenthesis.

Table 7: Robustness results. 
formly distributed across A, B and both for all firms, and several other values. In all cases, the algorithm finds one and only set of probabilities that satisfy the equilibrium conditions. We conclude that each of the models estimated here contain only one equilibrium. As suggested above, there is enough asymmetry between firms to rule out multiple equilibria.

To summarize, we find evidence consistent with our central hypothesis, that competition shaped ISP decision making over modem choice. We show that competition consistently pushed behavior towards differentiation. ISP's were less likely to adopt a standard as more of their competitors adopted that standard.

\section{Sources of Adoption Delay}

As it turned out, $56 \mathrm{~K}$ modem sales to ISP's went very slowly relative to the hopes of the modem producers. As we discussed, barely $50 \%$ of ISP's adopted 56K by October 1997. Furthermore, none of the large ISP's (AOL, AT\&T, UUNET, MSN, GTE, Bell-South, EarthLink) adopted. Due to the large skew in market share (e.g. twenty firms serve more than three quarters of the users), the vast majority of customers could not use 56K unless they switched from their existing large ISP to one of these smaller ISPs. Most consumers did not make this switch, even though most geographic regions had at least one or more ISP carrying 56K. Accordingly, sales to consumers were much less than the modem manufacturers expected.

Beyond expecting greater sales, industry participants expected the market to coordinate on a single standard. The sponsors of the two technologies engaged in a "standards war," with deep discounts as well as marketing promotions arguing that their technology would be the widely adopted standard.

Rockwell and USR both felt that the source of the slow sales was the standards battle and turned to the International Telecommunications Union, associ- 
ated with the United Nations, to set a standard. The ITU announced the V.90 standard, an amalgam of X2 and Flex (but incompatible with both), in February 1998. At the time, this was regarded as the shortest period of time the ITU had ever required to reach a decision. (Press Release ITU/98-4). Although the ITU had no jurisdiction in this market, it created a focal point for the industry. Sales were very strong thereafter and we interpret this widespread adoption by both ISP's and consumers as evidence of the value of coordinating on a single standard.

Given the importance of standardization, why were consumers and ISP's unable to coordinate without the ITU? What role did the differentiation by ISP's identified above play in that process? In this section, we argue that differentiation may have prolonged adoption delay.

Intuitively, network effects provide a force in favor of "tipping" towards one technology or the other. Even with many geographically dispersed markets and dispersed decision making, theory would lead one to expect local "tipping." That, in turn, might give rise to quick national unification of all local markets on the same standard or geographic balkanization, with Chicago and Atlanta tipping one way, Cleveland and Denver another, and so on. Instead, our tests show that there was no coordination at any level.

Can such splitting result in adoption delay if competition is strong enough? If consumers prefer a coordinated market and observe a split market, they may delay adoption until one of the two technologies emerges as a standard. Our model of how this might work is formalized in Rysman (2003a). In Rysman (2003a), consumers and firms play a dynamic adoption game choosing between two standards. Adopting a standard allows the adopter to trade with other adopters. Firms draw random fixed costs of adoption for each standard in each period. For particular parameter values, the model exhibits an equilibrium with adoption delay. A small group of technology-loving consumers adopt each standard in the first period. The remaining consumers delay their adoption 
until a critical number of firms adopts one standard or the other. Knowing this, firms avoid the standard with more firms on it in order to take advantage of the higher margins available on the other standard. This differentiation by firms justifies the consumers' decision to delay adoption as they cannot guess which standard will gain widespread acceptance. This equilibrium is more likely to exist if competition is very fierce as it causes firms to avoid competition. This models sets up the association between differentiation and delay that we claim took place in the $56 \mathrm{~K}$ market. ${ }^{28}$ The results of this model differ from most previous work on network effects, which would predict coordination in a case with homogenous technologies like the $56 \mathrm{~K}$ modems.

However, if a delay in standardization happened for some reason other than ISP differentiation, we might still expect to see ISP's differentiating in response to consumer behavior. Here we discuss explanations for adoption delay alternative to ISP differentiation. One possible explanation for the high sales of modems in 1998 could be that there was a substantial increase in demand for modems and Internet in early 1998 unrelated to standardization. We are skeptical of this explanation since the fastest period of growth in Internet adoption was already under way in 1997. For instance, there were already thousands of ISPs in the US, providing service to all but a small part of the US population (Downes and Greenstein, 2002). Second, the ITU's design for the V.90 did not differ functionally from either the X2 or Flex standards, and yet the introduction of the V.90 generated enormous growth in demand. Another alternative is that consumers were waiting for a new technology in 1997 (such as ISDN or

\footnotetext{
${ }^{28}$ Chou and Shy (1990) and Church and Gandal (1992) also consider models where multiple networks exist when efficiency calls for a single network. They rely on consumer heterogeneity but Church and Gandal specifically note the inefficient incentives of software providers to differentiate across standards. Ellison and Fudenberg (2002) indentify a similar issue in a more general setting and with homogenous standards. All three of these papers study static games where all consumers adopt. Rysman (2003a) shows in a dynamic game that the choice between standards can lead consumers to delay adoption, a particularly inefficient result.
} 
cable modems) that they gave up on in 1998 in favor of $56 \mathrm{~K}$ modems. We find these hypotheses implausible.

We believe that most compelling alternative explanation is that market participants were waiting for the ITU decision. Indeed, deliberations over $56 \mathrm{~K}$ modems at the ITU took place as early as November 1996 and the ITU claimed that it would announce a standard about two years after the introduction of the modem. However, there are a number of reasons to believe that the market could have progressed before the ITU decision. First, it is not clear how credible the ITU's scheduling claims were. Two years would be very quick relative to previous ITU decisions. Farrell (1996) reports that similar organizations deliver standards in 5 years, on average. Also, the ITU had no enforcement power in this case, it served only to create a focal point. If one technology could emerge as the market standard, it might not matter what the ITU's decision was. Even two years was considered a long time in this industry, enough time to establish a private standard. Furthermore, the ITU might pick one standard unmodified. In the ITU's previous interaction with the modem industry, it chose Rockwell's model for the $33.6 \mathrm{~K}$ standard almost unmodified. Again, success in the private market could influence the ITU along these lines. As evidence that the market was not waiting for the ITU, note that the sponsors of the two technologies competed very aggressively on the market to become the $56 \mathrm{~K}$ modem standard. ${ }^{29}$

Another possibility for why there was adoption delay is that consumers were simply confused. It was a new product and consumers had little information as to which standard to pick so they waited. We believe that this explanation is consistent with our story. Indeed, we would expect consumers that adopt before a standard is set to choose randomly. Our point is that one source of consumer

\footnotetext{
${ }^{29}$ Also, note that it would have been difficult for the ITU to act without industry support. There is evidence that Motorola prevented the advent of a new standard at an earlier ITU meeting by demanding high licensing fees for a patented technology. (Greene, 1997)
} 
confusion is that ISP's split evenly between the two standards. Similar to confused consumers, we could lay the blame at PC makers because they did not pick a default $56 \mathrm{~K}$ modem technology to bundle with computers. But, as with consumer adoption, the explanation for this behavior must be that PC makers could not predict which standard would gain acceptance, which presumably is at least partly because PC makers observed ISP's evenly separating across standards.

Note that Shapiro and Varian (1999) discuss the tactics by sponsors of competing standards, both in general and in the particular case of $56 \mathrm{~K}$ (on pages 267-270). Their general discussion focuses on characterizing a standards battle and deducing whether tactics are aligned with market incentives. Their discussion of the $56 \mathrm{~K}$ modem case is broadly consistent with ours. However, they do not offer a detailed explanation of why there was adoption failure previous to the ITU decision and do not consider incentives to differentiate across the standards by ISPs. ${ }^{30}$

\section{Conclusion}

This paper studies the importance of competition in technology adoption. We exploit a unique data set on the standardization process for $56 \mathrm{~K}$ modems in numerous geographically independent markets. We show that Internet Service Providers split evenly across the two available standards in local markets, confirming the importance of competition. We show that ISP's split much more evenly than independent random choice would predict with the dartboard index of Ellison and Glaeser (1997). We confirm this result in a bivariate probit frame-

\footnotetext{
${ }^{30}$ Shapiro and Varian suggest a faster diffusion process then we do prior to the ITU decision, relying mostly on announced adoption decisions for source material. Most of these announcements come from the medium to large firms. As they point out, many of these announcements were not followed by deployment. We follow our data source about deployments and report non-deployment for the largest firms. See Rickard (1997a,1997b, 1998).
} 
work that controls for ISP characteristics, demographics and decision-making by ISP's in multiple markets. Finally, we verify the result in a model based on an entry game of imperfect information that controls for the endogeneity of entry between rival ISP's. The fact that competitive forces are so strong is particularly surprising given the presence of an indirect network effect between ISP and consumer adoption of a 56K standard.

We use this result to consider a new hypothesis about adoption delay in a standards war. Previous theoretical work typically predicts that when network effects are present, competition between two undifferentiated technologies should lead to relatively quick standardization. However, this market failed to standardize without the intervention of a standard-setting organization. The result that ISP's differentiated across markets is consistent with our theory (formalized in Rysman, 2003a) that competitive differentiation across standards caused consumers to delay their adoption, and ultimately necessitated the intervention of the standard-setting organization. More broadly, the competitive environment of service providers may be an important determinant in the success or failure of a standards war, a previously overlooked issue by researchers, policy makers and private-sector managers.

\section{Appendix}

Details on computing the fixed point algorithm: We can write $E\left[\Pi_{j}^{s}\right]$ as:

$E\left[\Pi_{j}^{s}\right]=x_{j}^{f} \beta_{2}+\frac{1}{I} \sum_{i \in \vartheta_{j}} x_{i}^{l} \beta_{1}+\psi_{1} \frac{1}{I} \sum_{i \in \vartheta_{j}} E\left[n_{i}^{s} \mid \mathbf{X}, \theta\right]+\psi_{1}+\psi_{2} \frac{1}{I} \sum_{i \in \vartheta_{j}} E\left[n_{i}^{A B} \mid \mathbf{X}, \theta\right]$

Let $\Lambda(j)$ be the set of firms that overlap with $j$ and let $\lambda_{j k}$ be the number of switches at which $j$ overlaps with $k$. Then we have that:

$$
\sum_{i \in \vartheta_{j}} E\left[n_{i}^{s} \mid \mathbf{X}, \theta\right]=\sum_{i \in \vartheta_{j}} \sum_{k \in \Upsilon(i)} P_{k s}=\sum_{k \in \Lambda(j)} \lambda_{j k} P_{k s}
$$


Therefore, the average expected number of entrants faced by firm $j$ depends only on the number of locations at which $j$ faces entrants and their entry probabilities, not on where $j$ faces them. That is, facing 3 markets with one potential entrant in each has the same competitive implications as facing 2 markets with no potential entrants and 1 market with 3 , assuming entry probabilities are the same. This feature allows us to solve the fixed point algorithm in an economical manner. Let $\boldsymbol{\Lambda}$ be an $n \times n$ matrix with $\lambda_{j k}$ in position $j, k$ with $\lambda_{j k}=0$ if $j=k$. Let $\psi$ be the $4 \times 1$ matrix with elements 1,2,3 and 4 measuring the competitive impact of firms adopting none, the same standard, the other standard and both. In our implementation, $\psi=\left[0, \psi_{1}, 0, \psi_{2}\right]$ for Flex and $\psi=\left[0,0, \psi_{1}, \psi_{2}\right]$ for X2. Then:

$$
E\left[\Pi_{j}^{s}\right]=x_{j}^{f} \beta_{2}+\frac{1}{I} \sum_{i \in \vartheta_{j}} x_{i}^{l} \beta_{1}+\mathbf{\Lambda} \mathbf{P} \psi+\psi_{1}
$$

Solving the fixed point algorithm consists of picking a starting matrix $\mathbf{P}^{0}$, plugging into Equation 5 and plugging the result into Equation 2 to obtain a new matrix of adoption probabilities $\mathbf{P}^{1}$. We can iterate this way until convergence. The term $\sum_{i \in \vartheta_{j}} x_{i}^{l} / I$ can be computed once at the beginning of the estimation algorithm, further reducing the computational burden.

Note how restricting the competitive impact to be linear reduces the computational burden: we need only know the number of locations at which any firm overlaps with any other firm. If we were to add square terms, we would need to know the number of locations at which a firm overlaps with any pair of competitors and cubic terms require us to know the how many locations a firm overlaps with any triplet. Putting in a more complicated term, such as the ratio of adopters of one standard to the other, would likely requires us to loop through every firm-location combination in the data (more than 200,000 items) and would be infeasible to our knowledge. It is straightforward to add these terms to the analysis that assumes exogeneity and we found that it did not change the analysis. For instance, adding squares of the number of competitors 
adopting one of the choices does not change any of the results in a substantial way.

\section{References}

[1] Ackerberg, D and G. Gowrisankaran (2003) "Quantifying Equilibrium Network Externalities in the ACH Banking Industry," mimeo, UCLA.

[2] Amemiya, T (1985) Advanced Econometrics, Harvard University Press, Cambridge.

[3] Armstrong, M. (2002) "Competition in Two-Sided Markets," mimeo, Oxford University.

[4] Aguirregabiria, V and P. Mira (2002) "Identification and Estimation of Dynamic Discrete Games," mimeo, Boston University.

[5] Augereau, A, and S. Greenstein (2001)," The Need for Speed in Emerging Communications Markets: Upgrades to Advanced Technology at Internet Service Providers." International Journal of Industrial Organization, v 19, pp 1085-1102.

[6] Besen S.M. and L. Johnson (1986), Compatibility Standards, Competition, and Innovation in Broadcasting Industry, Rand Report, R-3453/1-Nsf.

[7] Berry, S.T. (1992) "Estimation of a Model of Entry in the Airline Industry," Econometrica, 60(4), 889-917.

[8] Berry, S. and A. Pakes (2002) "Two Estimators for the Parameters of Dynamic Discrete Games," mimeo, Harvard University.

[9] Church, J. and N. Gandal (1992) "Network Effects, Software Provision and Standardization," Journal of Industrial Economics, 40(1) 85-103.

[10] Chou, C. and O. Shy (1990) "Network Effects without Network Externalities" International Journal of Industrial Organization, 8 259-270.

[11] Dranove, D and N. Gandal (2003) "The DVD vs. DIVX Standard War: Empirical Evidence of Network Effects and Preannouncement Effects, "Journal of Economics and Management Science., 12 (3), pp. 363-386.

[12] Downes, T. and S. Greenstein (1999), "Universal Access and Local Commercial Internet Markets "Research Policy, 31, 1035-1052.

[13] Ellison, G. (1997) "Geographic Concentration in U.S. Manufacturing Industries: A Dartboard Approach," Journal of Political Economy, 105(5) 889-927. 
[14] Ellison, G. and D. Fudenberg (2003) "Knife Edge or Plateau: When Do Market Models Tip?" MIT Department of Economics Working Paper No. 03-07.

[15] Farrell, J. (1996) "Choosing Rules for Formal Standardization," mimeo, University of California, Berkeley.

[16] Gandal, N., M. Kende and R. Rob (2000), "The Dynamics of Technological Adoption in Hardware/Software Systems: The Case of Compact Disc Players", Rand Journal of Economics, 31, 43-61.

[17] Genesove D, (1999) "The Adoption of Offset Presses in the Daily Newspaper Industry in the United States," NBER Working Paper 7076.

[18] Gourieroux, C and A. Monfort (1995) Statistics and Econometric Models: Volume 1. Cambridge University Press, Cambridge.

[19] Gowrisankaran, G. and J. Stavins (2002) "Network Externalities and Technology Adoption: Lessons from Electronic Payments," RAND Journal of Economics, forthcoming.

[20] Greene, T (1997) "More Bumps in the Road for 56K modems," Network World, September 22, 1997, p12.

[21] Greenstein, Shane (2000) "Building and Delieverying the Virtual World: The Commercial Internet Access Market", Journal of Industrial Economics

[22] Haile, P.A., A. Hortascu and G. Kosenock (2003) "On the Empirical Content of Quantal Response Equilibrium," mimeo, Yale University.

[23] Klepper, S. (2002) "Firm Survival and the Evolution of Oligopoly," Rand Journal of Economics, 33(1) 37-61.

[24] Manski, C. (1993) "Identification of Endogenous Social Effects: The Reflection Problem," Review of Economic Studies, 60, 531-542.

[25] McKelvey, R.D. and T.R. Palfrey (1995) "Quantal Response Equilibrium for Normal Form Games," Games and Economic Behavior, 10(1), 6-38.

[26] Mulligan, J.G. and E. Llinares (2003) "Market Segmentation and the Diffusion of Quality-Enhancing Innovations: The Case of Downhill Skiing," Review of Economics and Statisitcs, 85(3), 493-502.

[27] National Telecommunications Information Administration (2002),. "A Nation Online: How Americans Are Expanding Their Use Of The Internet.' http://www.ntia.doc.gov/reports.html.

[28] Ohashi, H (2000) "Network Externalities and Consumer Welfare: Home Video Cassette Recorders in the U.S., 1978-1986" mimeo, University of British Columbia. 
[29] Park, S (2000) "Quantitative Analysis of Network Externalities in Competing Technologies: The VCR Case," mimeo, SUNY-Stony Brook.

[30] Pesendorfer, M and P. Schmidt-Dengler (2003) "Identification and Estimation of Dynamic Games," mimeo, London School of Economics.

[31] Postrel, S (1990) "Competing Networks and Proprietary Standards: The Case of Quadraphonic Sound," Journal of Industrial Economics, 39(2), 169-185.

[32] Rickard, J (1998) "The 56K Modem Battle," Boardwatch, March 1998.

[33] Rickard, J (1997a) "56K Modems: The Battle Continues," Boardwatch, March 1997.

[34] Rickard, J (1997b) "U.S. Robotics Launches the New Battle - 56Kbps Modems" Boardwatch, January 1997.

[35] Rochet, J.-C. and J. Tirole (2002) "Platform Competition in Two-Sided Markets" mimeo, University of Toulouse.

[36] Rohlfs, J (2001) Bandwagon Effects in High Technology Industries, MIT Press, Cambridge.

[37] Rysman, M. (2003a), "A Standards War Under Indirect Network Effects," mimeo, Boston University.

[38] Rysman, M. (2003b), "Competition Between Networks: A Study of the Market for Yellow Pages," Review of Economic Studies, forthcoming.

[39] Rysman, M. and S. Greenstein (2003), "Testing for Agglomeration and Dispersion," mimeo, Boston University.

[40] Saloner, G. and S. Shepard (1995) "Adoption of Technologies with Network Effects: An Empirical Examination of the Adoption of Automated Teller Machines" Rand Journal of Economics, 26, 479-501.

[41] Shapiro, C., and H. Varian (1999), Information Rules: A Strategic Guide to the Network Economy, Harvard Business School Press, Cambridge.

[42] Shy, O. (2001) The Economics of Network Industries, Cambridge University Press, Cambridge.

[43] Seim, K. (2002) "An Empirical Model of Firm Entry with Endogenous Product-Type Choices," mimeo, Stanford University GSB. 